\title{
Enhancing Intrinsic Motivation through Innovation in Voice Ball for the Blind
}

\author{
Febriana Pratiwi*, Amung Ma'mun, Yudy Hendrayana \\ Postgraduate School \\ Universitas Pendidikan Indonesia \\ Bandung, Indonesia \\ *febrianapratiwi@upi.edu, amungmamun@upi.edu
}

\begin{abstract}
The purpose of this study is to identify and analyze the intrinsic motivation of learning in children with blind through the application of innovative learning media through voice ball in physical education. An experimental research method using a one group pretest-posttest design. Treatment is done at Wiyata Guna special needs school in Bandung City, Indonesia. Participant in this study were of 6 males and 4 females. The instrument is a questionnaire consisting of 27 items adopted from Motivation Strategies for Learning Questionnaire (MSLQ). Data were analysed using t-test. Result of the posttest showed a significant influence on student's intrinsic motivation by applying innovation of voiced ball learning media in physical education $(p<0.05)$. As a conclusion, innovation of voiced ball learning media is highly recommended for teachers of physical education to improve intrinsic motivation in children with blind, so that the learning objectives of physical education can be achieved optimally.
\end{abstract}

Keywords-blind; intrinsic motivation; physical education; voiced ball

\section{INTRODUCTION}

Motivation is seen as a mental impulse that moves and directs human behavior, including learning behavior. In motivation there is a desire that allows, moves, distributes, and trains individual learning [1]. The first obstacle to motivation along with students' intrinsic motivation. Problems arise in the uniqueness of each individual because what allows students to learn may not motivate others. Therefore, training some students in carrying out the task of motion as an unpleasant task, learning media that is less attractive and makes intrinsic motivation disappear. Students who intrinsically do something to seek pleasure or challenge. External benefits and rewards are not needed to encourage motivation [2].

This increase in intrinsic motivation is very necessary for students in the process of learning physical education. High intrinsic motivation encourages students to be diligent in practicing, diligent and eager to practice. So with the high intrinsic motivation that students have, it can support better learning achievement. Likewise, if the student's intrinsic motivation is low, the enthusiasm for learning will be reduced and the learning outcomes will be questioned. This can be done by the teachers, especially in how to provide a spiritually encouraging encouragement with intrinsic motivation. Physical education learning will run poorly if the teacher uses only the facilities and infrastructure that are inadequate without the creativity being done, even though the use of good and appropriate facilities will facilitate the achievement of learning objectives. By using means of learning or tools, students will more easily accept and understand the material delivered by the teacher. Especially for children with blind.

Motor learning for blind students is very important. As much as possible physical education learning for blind students can improve the quality of motor development. The use of appropriate learning facilities will help and motivate them to continue learning. One of the factors that triggers intrinsic motivation for blind students is through modification or innovation in learning media. The right learning media will greatly facilitate the achievement of physical education learning goals. The most important thing is that the successful outcome of learning physical skills is to create an environment in which students are encouraged and motivated to experience various forms of movement [3].

For young people the inability to see raises the risk of reduced participation and social exclusion. They face challenges in various fields of their lives. Young people with disabilities often experience longer childhood than their peers, for example, are too protective of their parents and helpers, lack of assistive devices, or the nature of their disability [4]. Blind students generally have problems with their motor development. Especially for total blind students who lose sight from an early age. The more limited seeing, the more constrained the motoric development. Total blind students also tend to have poor posture. This is because they often bend and grope objects in front of them. So their ability in running and throwing is not good either. People who experience an inability to see or are called totally blind they have no visual perception, so to understand everything they depend on other senses, especially on the senses of hearing, touch and smell [5].

Innovation of learning media in the form of voiceless ball for blind students still needs to be developed to help increase the intrinsic motivation of students with total blindness in carrying out physical activities. The voiced ball that is often used by total blind students is the ball in which is given a sound that comes from bells or sand. But the sound generated from the ball is still very limited, the new ball will sound or make a sound when the ball is moved. If the ball is still or without 
movement, the ball will not sound. The limited sound released by the ball can inhibit students' independence and intrinsic motivation in learning. If in playing ball students still depend on other people or the alert person, it can reduce independence and intrinsic motivation to play on students. Therefore, a solution is needed to create a special ball for students who are totally blind who can consistently produce sounds even though the ball is in a stationary or unmoving position, combining the use of technology will provide support to the teacher's goal to motivate all students in physical education so as to foster the intrinsic motivation of students with total blindness to move or play with the ball [6]. The purpose of this article is to identify and analyze voiced ball use in learning physical education for students with total blindness to improve intrinsic motivation.

\section{METHOD}

\section{A. Study Design}

The method used in this research is the experimental method. The research design used is One Group Control Pretest-Posttest design.

\section{B. Participants and Procedures}

Participants in this study were students with total blindness at the Bina Netra Social Institution (PSBN) in Bandung Wiyata Guna as many as 10 students consisting of 6 male students and 4 female students. The treatment that was given was using an innovative sound ball learning media in physical education learning for 8 meetings for students with total blindness. The treatment procedure has been arranged in a learning scenario that has been previously designed.

The research procedures carried out are: (1) Conducting preliminary observations through interviews with physical education teachers in PSBN Wiyata Guna to obtain information about: (a) the implementation of the learning done by the teacher in learning physical education for blind students, (b) obstacles faced in the implementation of physical education learning and how to overcome them, and (c) data studies as literature studies; (2) Agreeing on the implementation of learning with the teacher, namely the implementation of voiceball learning media innovations in physical education for blind students.

In this study, the teacher carried out the learning process, while the writer acted as an observer and teacher partner. Furthermore, learning is carried out according to the planned schedule; (3) Planning, namely preparing a research plan, including the abilities needed in conducting research, the formulation to be achieved in accordance with the research, and research steps; (4) Conduct an instrument test, namely by asking the consideration of the instrument used to be consulted to psychologists and special education teachers with a focus on the study of blind people (expert judgment) to consider whether the instrument is suitable for use or not; (5) Provide pretest of learning motivation of blind students in the experimental class; (6) Introducing voiceless media learning innovations in learning physical education for students at home; (7) Provision of treatment (treatment) to the experimental class by using voice ball learning media innovations.

\section{Instrument}

The instrument used was a questionnaire instrument based on the Motivation Strategies for Learning Questionnaire (MSLQ) questionnaire developed by Pintrich and DeGroot. This questionnaire consists of 27 statement points which is a description of the statement containing 4 Intrinsic Goal Orientation, 3 extrinsic Goal Orientation statements, 4 Task Value statements, 3 Control of Learning Belief statements, 8 Self-Efficiency for Learning \& Performance statements, 5 questions Anxiety Test.

This questionnaire uses a Likert scale with 4 assessment criteria, namely assessment 1 if the respondent strongly disagrees with the statement, score 2 if the respondent does not agree to the statement, score 3 if the respondent agrees with the statement, a score of 4 respondents strongly agrees with the statement.

\section{RESULTS AND DISCUSSION}

The main purpose of this study was to explore the effect of the application of voiceless media on the intrinsic motivation of blind students, because children with blind had worse object control quality than children who were seen [7]. Referring to the results of the study that students with total blindness in PSBN Wiyata Guna before using voiceless ball in physical education learning there is a change in post-test results that are better than the pre-test on intrinsic motivation in accordance with the results of paired T-test, with $=0.05, \mathrm{t}$ count is greater than $t$ table (13.756> 2.879). So in other words, it can be concluded that there is a significant influence on the voiceless learning media innovation in increasing the intrinsic motivation of students with total blindness.

The application of voiced ball use in physical education learning is carried out in PSBN Wiyata Guna. Physical education learning has a role in giving students the opportunity to be directly involved in various learning experiences, this is important because of their impact on child development, education, and quality of life through physical and sports activities carried out systematically [8]. Young people have an innate desire to be active, and are the responsibility of physical education specialists to fulfill this desire. The concept of promoting intrinsic motivation, the motivation to engage in activities for pleasure and mere satisfaction is often of concern in the context of learning physical education. Children who have intrinsic motivation are more likely to experience their physical activity as positive, thus bringing them closer to a physically active lifestyle [9].

Teachers must be able to motivate and motivate students to want to learn more actively to achieve higher achievement. Motivation is a condition or internal status that directs a person's behavior to actively act in order to achieve a goal [10]. For this reason, the teacher needs to try to understand the condition and character of each student in order to be able to find the appropriate form of motivation for students. As a good motivator, physical education teachers must understand the three keys to motivate students to practice. On the other hand, 
Adang reported three keys to motivate students to practice are as follows: 1) Oriented to success, meaning that physical education teachers must be able to create and change the form of appropriate skills learning activities, able to encourage students to be able to adjust skill levels with the ability level, able to make students enjoy learning activities; 2) Intrinsically motivating, physical education teachers must be able to encourage students to work hard so that students gain satisfaction from the learning outcomes they achieve; 3) In accordance with the level of development, physical education teachers must be able to create learning activities that can reflect different levels of ability and age of students, thus encouraging students to work hard and students remain active in carrying out their learning activities [11].

Teachers need to apply learning media innovations that are appropriate to the characteristics of students. Through the innovation of voiceless ball learning media in the learning, students get motion activities that can cause pleasure, joy and freedom so that students are more motivated towards learning. The intended ball is a learning medium that provides pleasure for students with total blindness, because when the ball is used to have a consistent sound, students will remain active and enthusiastic in the implementation of learning. The sound contained in the ball can be adjusted according to circumstances and situations, so that it can be done anywhere. Innovation of voiceless media needs to pay attention to the feasibility of use in accordance with the characteristics of students with total blindness, namely the ball must be light, brightly colored, and equipped with sound components that can sound constantly even though the ball is still. In this learning, fun is the main key in supporting the game of students with total blindness. Therefore, students who can feel happy while using a voice ball in physical education learning will greatly help these students to be motivated in learning. Voice-ball media innovation helps to attract children's interest and improves attitudes towards the task of motion given by the teacher. They become more critical of the completion of their own and others' movements, their understanding and appreciation grow. A manifestation of this lies in the fact that the media of constant sound for students with total blindness makes them motivate each other. With experience and consideration of related practices, it is possible to provide voiceless media innovation for physical education programs for students who are totally blind at all levels of education.

\section{CONCLUSION}

The voiced ball is an innovative learning media as a provider of facilities and support to increase intrinsic motivation and expand opportunities to participate in physical activity for students with total blindness. The ball is designed primarily to enable people with total blindness to have motivation in participating and enjoying team sports activities while considering their unique needs. Sports activities that make the ball as a tool in games such as baseball and soccer greatly enhance the emotional, physical and personal development of individuals with total blindness. Students' total blind participation in physical activity not only reduces individual health risks such as obesity, but improves overall quality of life by promoting mutually motivating friendships.

The innovation of the ball learning media in the teaching and learning process is not only used for physical education learning but can also be used in daily sports activities. In order to get maximum results in learning with the use of innovative ball learning media in increasing the intrinsic motivation of students with total blindness, the learning media innovation must be adapted to the abilities and conditions of students so that students can follow the learning process freely, happily and not afraid of injury and there can be changes in behavior towards a better direction.

\section{REFERENCES}

[1] A. Papaioannou, "Students' perceptions of the physical education class environment for boys and girls and the perceived motivational climate," Research Quarterly for Exercise and Sport, vol. 69, no. 3, pp. 267-275, 1998.

[2] M. Kilpatrick, E. Hebert, D. Cst Jacobsen, "Physical activity motivation: A practitioner's guide to self-determination theory," Journal of Physical Education, Recreation \& Dance, vol. 73, no. 4, pp. 36-41, 2002.

[3] B.L. Alderman, A. Beighle and R.P. Pangrazi, "Enhancing Motivation in Physical Education," Journal of Physical Education, Recreation \& Dance, vol. 77, no. 2, pp. 41-51, 2006

[4] H. Ahponen, "Transition to adulthood of severely disabled adolescents," Diversity in individual life courses, 2008.

[5] B. Smith and E.W. Hill, The development of a motor curriculum for preschool children with visual impairments. 2014.

[6] C.M. Mowling, K.K. Eiler, S.J. Brock, and M.E. Rudisill, "Studen Motivation in Physical Education," JOPERD: The Journal of Physical Education, Recreation \& Dance, vol. 75, no. 6, pp. 40-51, 2004.

[7] S. Houwen, C. Visscher, E. Hartman, and K.A.P.M. Lemmink, Gross Motor Skills and Sports Participation of Children. 2013.

[8] J.B. Shrestha, S. Gnyawali and M.P. Upadhyay, "Causes of blindness and visual impairment among students in integrated schools for the blind in Nepal," Ophthalmic Epidemiology, vol. 19, no. 6, pp. 401-406, 2012.

[9] M.R. Weiss, "Motivating kids in physical activity," The President's Council on Physical Fitness and Sports Research Digest, vol. 3, no. 11, pp. $1-8,2000$

[10] M. Carver and C. Colestock, Motivation of Child Interest. 2013.

[11] A. Suherman, Revitalisasi Pengajaran dalam Pendidikan Jasmani. Bandung: CV Bintang Warli Artika, 2009 